\title{
A Call for Papers
}

\section{Substance Abuse: Innovations In Primary Care}

$T_{\text {pat }}$ GIM plans to publish a special issue devoted to aspects of addressing alcohol, tobacco, and illicit drug use in patients seen in the primary care setting. This call for papers comes at a time when substance abuse issues are being recognized increasingly as mainstream general internal medicine concerns. This shift has occurred over the past decade as the importance of substance abuse disorders in medical practice has become well established. It has been estimated that alcohol consumption is responsible for over 100,000 deaths annually and over $\$ 100$ billion in economic costs in the United States. ${ }^{1}$ When the impact of tobacco and illicit drug use is added to these figures, the total number of deaths per year increases to over $500,000^{2}$ and total economic costs are approximately one quarter of a trillion dollars. ${ }^{3}$

Underlying these findings regarding substance userelated mortality and costs is the fact that the use of alcohol, tobacco, and drugs has been closely linked to a variety of medical and psychosocial problems, all of which may prompt a visit to a primary care physician or health care facility. For example, over $25 \%$ of admissions to community hospitals are alcohol related ${ }^{4}$ and the prevalence of alcohol abuse or dependence ranges from $16 \%$ to $36 \%$ in outpatient medical settings. ${ }^{5}$ A recent study of adult primary care patients demonstrated that $60 \%$ used alcohol, of whom 9\% were at-risk drinkers, $8 \%$ were problem drinkers, and 5\% were alcohol dependent. ${ }^{6}$ Data from this same study showed that $27 \%$ of these primary care patients used tobacco, and at least $20 \%$ had a history of illicit drug use, of whom $5 \%$ were current illicit drug users. ${ }^{6}$ Such studies give compelling evidence that substance use disorders are prevalent in primary care practice. Physicians need to be prepared to deal with these issues. Yet, we have a suboptimal record of identifying and addressing patients' needs in this regard in both inpatient and outpatient settings. ${ }^{4,7}$

Recognition of the importance of alcohol, tobacco, and other drug abuse disorders in primary care practice has resulted in a call for primary care physicians to take a larger role in the identification and management of substance use disorders. ${ }^{8-11}$ These disorders are after all quite similar to other problems managed by primary care physicians. They are characterized by a chronic course with periodic exacerbations and have both medical and psychosocial sequelae. Perhaps more importantly, these conditions can be identified by well-established screening methods and do respond to effective treatment.

Recent research on the identification and treatment of substance use disorders has focussed on primary care settings. Increasingly, this research is being performed by investigators who are from fields such as General Internal Medicine, General Pediatrics, and Family Medicine. For example, major advances in the identification of effective 70 screening methods for alcohol use disorders have been the result of research done in primary care settings by generalist physicians. As a result of this work, we now understand the utility of screening instruments such as the CAGE and the AUDIT and know the importance of early identification of alcohol problems. ${ }^{12-20}$ In addition, evidence is convincing that effective management of "at risk" and problem drinking and tobacco use can be delivered in the primary care setting. ${ }^{21-24}$ Even the treatment of illicit drug use with pharmacotherapies that historically were restricted to specialized treatment programs may soon become the province of primary care. ${ }^{25}$

The Society of General Internal Medicine's (SGIM) Substance Abuse Task Force has been at the forefront of these developments. The Task Force's members are among the leading investigators, educators, and clinicians in the substance abuse field. The group has taken a leadership role in bringing issues related to substance abuse "into the fold" of SGIM and generalist physicians in other fields. ${ }^{26}$ At the 2000 SGIM national meeting, the Task Force decided to seek publication of a special issue of JGIM which would focus on substance abuse. With the support of the Josiah Macy Foundation and the Physician Leadership on National Drug Policy (PLNDP), the Task Force will be sponsoring the publication of this issue entitled "Substance Abuse: Innovations in Primary Care" in early 2002.

This special issue will follow standard JGIM format, with all articles focussed on aspects of alcohol, tobacco and illicit drug use relevant to generalist physicians. Authors may submit original research articles, brief reports, reviews, perspectives, reflections, or articles appropriate for the Journal's new sections on Health Policy, Populations at Risk, and Innovations in Education and Clinical Practice (see JGIM's instructions for authors at http://www.blackwellscience.com/journals/internal/ form.html). The deadline for submission of articles is June 1, 2001. As Co-Chairs of the SGIM Task Force, we will serve as Co-Editors of this special issue. For further information concerning submission of original manuscripts or to volunteer to review articles, please contact Jeffrey Samet (jsamet@bu.edu) or Patrick O'Connor (patrick.oconnor@yale.edu).-PATrick G. O'Connor, MD, MPH, Yale University School of Medicine, New Haven, Conn, and Jefrrey H. Samet, MD, MA, MPH, Boston University School of Medicine, Boston Medical Center, Boston, Mass.

\section{REFERENCES}

1. Ninth Special Report to the United States Congress on Alcohol and Health: U.S. Department of Health and Human Services, 1997.

2. McGinnis JM, Foege WH. Actual causes of death in the United States. JAMA. 1993;270:2207-12. 
3. Institute for Health Policy, Brandeis University. Substance Abuse: The Nation's Number One Health Problem. Princeton, New Jersey: The Robert Wood Johnson Foundation; 1993.

4. Moore RD, Bone LR, Geller G, Mamon JA, Stokes EJ, Levine DM. Prevalence, detection, and treatment of alcoholism in hospitalized patients. JAMA. 1989;261:403-7.

5. O'Connor PG, Schottenfeld RS. Patients with alcohol problems. New Engl J Med. 1998;338:592-602.

6. Manwell LB, Fleming MF, Johnson K, Barry KL. Tobacco, alcohol, and drug use in a primary care sample: 90-day prevalence and associated factors. J Addict Dis. 1998;17:67-81.

7. Saitz R, Mulvey KP, Plough A, Samet JH. Physician unawareness of serious substance abuse. Am J Drug Alcohol Abuse. 1997; 23:343-54.

8. Lewis DC. The role of the generalist in the care of the substanceabusing patient. Med Clin North Am. 1997;81:831-43.

9. Weaver MF, Jarvis MA, Schnoll SH. Role of the primary care physician in problems of substance abuse. Arch Intern Med. 1999; 159:913-24.

10. The Physicians' Guide to Helping Patients With Alcohol Problems: National Institute on Alcohol Abuse and Alcoholism. The National Institutes of Health; 1995.

11. McLellan AT, Lewis DC, O'Brien CP, Kleber HD. Drug dependence, a chronic medical illness: implications for treatment, insurance, and outcomes evaluation. JAMA. 2000;284:1689-95.

12. Adams WL, Barry KL, Fleming MF. Screening for problem drinking in older primary care patients. JAMA. 1996;276:1964-7.

13. Barry KL, Fleming MF. The Alcohol Use Disorders Identification Test (AUDIT) and the SMAST-13: predictive validity in a rural primary care sample. Alcohol. 1993;28:33-42.

14. Buchsbaum DG, Welsh J, Buchanan RG, Elswick RK Jr. Screening for drinking problems by patient self-report. Even 'safe' levels may indicate a problem. Arch Intern Med. 1995; 155:104-8.
15. Fiellin DA, Reid MC, O'Connor PG. Screening for alcohol problems in primary care: a systematic review. Arch Intern Med. 2000; 160:1977-89.

16. Isaacson JH, Butler R, Zacharek M, Tzelepis A. Screening with the Alcohol Use Disorders Identification Test (AUDIT) in an inner city population. J Gen Intern Med. 1994;9:550-3.

17. Saitz R, Lepore MF, Sullivan LM, Amaro H, Samet JH. Alcohol abuse and dependence in Latinos living in the United States: validation of the CAGE (4M) questions. Arch Intern Med. 1999; 159:718-24.

18. Soderstrom CA, Smith GS, Kufera JA, et al. The accuracy of the CAGE, the Brief Michigan Alcoholism Screening Test, and the Alcohol Use Disorders Identification Test in screening trauma center patients for alcoholism. J Trauma. 1997;43:962-9.

19. Taj N, Devera-Sales A, Vinson DC. Screening for problem drinking: does a single question work? J Fam Pract. 1998;46:328-35.

20. Fleming MF, Barry KL. The effectiveness of alcoholism screening in an ambulatory care setting. J Stud Alcohol. 1991;52:33-6.

21. WHO Brief Intervention Study Group. A cross-national trial of brief interventions with heavy drinkers. Am J Public Health. 1996; 86:949-55.

22. Barnes HN, Samet JH. Brief interventions with substance-abusing patients. Med Clin North Am. 1997;81:867-79.

23. Fleming MF, Barry KL, Manwell LB, Johnson K, London R. Brief physician advice for problem alcohol drinkers. A randomized controlled trial in community-based primary care practices. JAMA. 1997;277:1039-45.

24. Ockene JK, Adams A, Hurley TG, Wheeler EV, Herbert JR. Brief physician- and nurse practitioner-delivered counseling for highrisk drinkers: does it work? Arch Intern Med. 1999;159:2198-205.

25. O'Connor PG. The treatment of opioid dependence - new data and new opportunities. N Engl J Med. 2000;343.

26. Samet JH, Stein MD, O'Connor PG. Alcohol and Other Substance Abuse. Med Clin North Am. 1997;81.

\title{
ANNOUNCEMENT
}

\section{You can reach JGIM on the Internet!}

\author{
For more information \\ about submitting manuscripts to JGIM \\ or if you would like to submit a \\ Letter to the Editor or a \\ short creative writing piece \\ for possible publication in the Journal, \\ please e-mail us at
}

jgim@jhmi.edu 